\title{
Article \\ Modifying HKUST-1 Crystals for Selective Ethane Adsorption Using Ionic Liquids as Synthesis Media
}

\author{
Gregory S. Deyko ${ }^{1, *}$, Lev M. Glukhov ${ }^{1}$, Vera I. Isaeva ${ }^{1, *}$, Vladimir V. Chernyshev ${ }^{2,3}{ }^{\circledR}$, Vadim V. Vergun ${ }^{1}$, \\ Danil A. Archipov $\left.{ }^{1}{ }^{(}\right)$, Gennady I. Kapustin ${ }^{1}{ }^{\circledR}$, Olga P. Tkachenko ${ }^{1}{ }^{\circledR}$, Vera D. Nissenbaum ${ }^{1}$ \\ and Leonid M. Kustov 1,3,* \\ 1 N.D. Zelinsky Institute of Organic Chemistry, Russian Academy of Sciences, 47 Leninsky Prospect, \\ 119991 Moscow, Russia; elektron77@mail.ru (L.M.G.); polubrat@mail.ru (V.V.V.); \\ arkhipov.danil2015@gmail.com (D.A.A.); gik@ioc.ac.ru (G.I.K.); ot@ioc.ac.ru (O.P.T.); vdn14@inbox.ru (V.D.N.) \\ 2 A.N. Frumkin Institute of Physical Chemistry and Electrochemistry, Russian Academy of Sciences, Building 4, \\ 31 Leninsky Prospect, 119071 Moscow, Russia; vladimir@struct.chem.msu.ru \\ 3 Department of Chemistry, M.V. Lomonosov Moscow State University, 1-3 Leninskie Gory, \\ 119991 Moscow, Russia \\ * Correspondence: gdeyko@gmail.com (G.S.D.); veraisaeva2019@mail.ru (V.I.I.); LMK@ioc.ac.ru (L.M.K.)
}

\section{check for}

updates

Citation: Deyko, G.S.; Glukhov, L.M.; Isaeva, V.I.; Chernyshev, V.V.; Vergun, V.V.; Archipov, D.A.; Kapustin, G.I.; Tkachenko, O.P.; Nissenbaum, V.D.; Kustov, L.M. Modifying HKUST-1 Crystals for Selective Ethane

Adsorption Using Ionic Liquids as Synthesis Media. Crystals 2022, 12, 279. https://doi.org/10.3390/ cryst12020279

Academic Editor: Vladimir P. Fedin

Received: 7 January 2022

Accepted: 16 February 2022

Published: 18 February 2022

Publisher's Note: MDPI stays neutral with regard to jurisdictional claims in published maps and institutional affiliations.

Copyright: (C) 2022 by the authors. Licensee MDPI, Basel, Switzerland. This article is an open access article distributed under the terms and conditions of the Creative Commons Attribution (CC BY) license (https:// creativecommons.org/licenses/by/ $4.0 /)$.

\begin{abstract}
Novel adsorbents for methane and ethane based on HKUST-1 metal-organic framework were synthesized by microwave (MW) assisted technique using ionic liquids (ILs) as synthesis media. It was found that the MW synthesis time remarkably impacts both the product yield and the physico-chemical characteristics of the produced HKUST-1 material. The crystalline phase purity, crystallite size/dispersion and textural properties of the synthesized HKUST-1 matrices determine their performance in methane and ethane adsorption. Therefore, the HKUST-1 material produced in MW fields for 3 min only shows the highest phase purity and the largest surface area (BET) and porosity, along with a rather small crystallite size (below $\sim 300 \mathrm{~nm}$ ), demonstrating high methane and ethane adsorption capacity in the pressure range 1-30 atm.
\end{abstract}

Keywords: metal-organic frameworks (MOFs); ionic liquids; methane; ethane; adsorption; selectivity

\section{Introduction}

Natural gas is the cleanest fuel among fossil-based resources [1]. It consists mainly of methane $(>90 \%)$ and other hydrocarbons (mostly ethane, up to $10 \%)$. It is mainly used as a fuel in industry and households, as well as in internal combustion engines. However, the combustion of methane-ethane mixture is not an optimal method because ethane is a promising precursor in the petrochemical synthesis for producing a number of valuable products, such as plastics [2]. Therefore, more efficient methods for the separation of components of natural gas are demanded.

To date, methods for natural gas processing based on the cryoseparation techniques, which involve liquefaction of natural gas at high pressures and low temperatures (10-15 bar, $100 \mathrm{~K})$, are used [3]. An alternate strategy, gas adsorption on porous materials, allows one to perform separation at room temperature and relatively low pressures (usually 0.1-5 bar) [4].

A novel type of hybrid nanoporous adsorbents, metal-organic frameworks (MOFs), are currently studied as promising materials for storage and separation of a large number of different gases [5]. MOF materials are crystalline coordination polymers composed of metal cations and polydentate organic molecules (linkers) [6]. Due to these unique properties, MOF matrices show a better configuration for the specific task (i.e., gas separation, catalysis, sensors) than their inorganic and carbon counterparts. In particular, the reason for adsorption/separation applications of MOFs is their record-high specific surface area and porosity, open-pore system, diverse chemical composition and tunable pore geometry and functionality [7]. 
A lot of efforts is devoted to the application of MOF materials in natural gas purification [8]. In particular, some methods are recognized as promising candidates for the separation of methane and ethane, i.e., HKUST-1 [9,10], SBMOF-1 and SBMOF-2 [11], DUT49 [12], DUT-75 [12] and ZnSDB (isostructural analogue of SBMOF-1) [13]. For instance, DUT materials show the highest methane adsorption capacity [12], e.g., $240 \mathrm{mg} / \mathrm{g}$ for DUT-75 (90 atm, $298 \mathrm{~K}$ ), and that of DUT-76 matrix is $308 \mathrm{mg} / \mathrm{g}$ under the same conditions, which is record-breaking today. However, most published works deal with single gas, methane or ethane, so it is rather problematic to evaluate the real separation performance of the reported MOF adsorbents due to different adsorption conditions in each cited work, e.g., pressure and temperature.

The HKUST-1 material is the most promising adsorbent known to date [12] for the purposes of separating natural gas components due to its high capacity for both methane and ethane, as well as the rather low cost of synthesis in comparison, for example, with the DUT-75 matrix.

HKUST-1 $\left(\mathrm{Cu}_{3}(\mathrm{btc})_{2}\right)$ metal-organic framework consists of $\mathrm{Cu}$ - $\mathrm{Cu}$ dimers, which are connected by benzene-1,3,5-tricarboxylate (btc) linkers to form a three-dimensional network with micropores in the range of $0.7-0.9 \mathrm{~nm}$. Due to this structure, the HKUST- 1 matrix features promising adsorption characteristics $[13,14]$.

In particular, the HKUST-1 material shows the adsorption capacity of $4.5 \mathrm{mmol} / \mathrm{g}$ (1 MPa, 303K) [15] for methane and about $3.5 \mathrm{mmol} / \mathrm{g}$ (1 bar, $313 \mathrm{~K})$ for ethane [16]. Note, this capacity value of HKUST-1 for methane meets the requirements of DOE (Department of Energy, Washington, DC, USA) for the capacity of solid sorbents relevant to their industrial use.

Currently, a number of different methods are proposed for the synthesis of the HKUST1 material, i.e., solvothermal procedure [17,18], MW-assisted solvothermal technique using templates [19], solvent-free vacuum growth [20], mechanochemical method [21], etc. All these methods can significantly affect most physicochemical properties of the produced HKUST-1 material, such as crystallinity, surface area (BET), pore volume, morphology, etc. Therefore, the correct choice of synthesis procedure may be a key factor which has a serious impact on the gas separation performance of the HKUST-1 adsorbent.

The crystal size and dispersion of the MOF product are determined by an appropriate choice of synthesis procedure. It is well-established that efficient nanocrystal size control is a key factor governing the possibility of application of the material, including MOF matrices for the specific task [22]. Various procedures are used to tune both the size and morphology of MOF materials, but the modification of the solvent composition is one of the most convenient methods [23].

Conventional solvents for MOF formation include water, $\mathrm{N}, \mathrm{N}$-dimethylformamide (DMF), N,N-diethylformamide, dimethyl sulfoxide and N-methylpyrrolidone. In particular, the use of mixed solvents based on water or ethanol (e.g., DMF/ethanol and DMF/water) was found to influence crystal growth through solvent-induced effects [24].

Currently, ionic liquids (ILs) are proposed as alternatives to traditional organic solvents for the ionothermal synthesis of MOF materials [25,26]. Ionic liquids are molten salts with a melting point below $100^{\circ} \mathrm{C}$, consisting of organic cations (usually dialkylimidazolium or tetraalkylmmonium) and various organic or inorganic anions, such as acetate $\mathrm{CH}_{3} \mathrm{COO}^{-}$, triflate $\mathrm{CF}_{3} \mathrm{SO}_{3}{ }^{-}$, tetrafluoroborate $\mathrm{BF}_{4}{ }^{-}$. In addition, ILs also feature versatility in choosing the cation and anion combination, highly tunable properties, high thermal stability, low vapor pressure and recyclability. The polar ILs provide a high solubility of both organic and inorganic reagents. In addition, the presence of cation and anion groups in the solvent can serve as charge compensating moieties during MOF synthesis [27]. Additionally, ILs are environmentally friendly solvents primarily due to their easy recovery.

In addition, using ILs as a solvent system makes it possible to reduce the MOF crystallite size efficiently. For instance, the use of ionic liquid microemulsions (ILMEs) is a relatively new technique for tuning the particle size distributions of MOFs [28]. 
Despite its advantages, ionothermal MOF synthesis usually requires a high temperature $\left(>100{ }^{\circ} \mathrm{C}\right)$ and long reaction time (3-12 days) to overcome the high enthalpies of the product formation or account for the slow kinetics of nucleation [29]. To conquer these obstacles, it was proposed in [30] to utilize $\mathrm{CO}_{2}$ as an activator to promote HKUST-1 material crystallization as ultra-small nanoparticles (NPs) in 1-butyl-3-methylimidazolium tetrafluoroborate $\left([\mathrm{BMIM}] \mathrm{BF}_{4}\right)$ at room temperature.

On the other hand, in the context of the efficient control of the morphology of MOF crystallites, MW-assisted synthesis shows particular potential. This technique is recognized as a promising strategy to efficiently manipulate the key physico-chemical characteristics of produced MOF materials [31-33].

MW-assisted synthesis using ILs as solvents is expected, under certain conditions, to provide enhanced physico-chemical properties of produced MOF materials. It is known that ILs are appropriate templates for microporous materials [34] and ideal microwave absorbers [35]. Furthermore, the heating rate in MW fields is significantly increased compared to traditional organic solvents since the ILs have a significantly higher ionic conductivity $[36,37]$.

Recently, we reported the impact of MW-assisted synthesis in the $\mathrm{H}_{2} \mathrm{O}-\mathrm{DMF}$ system at an atmospheric pressure using a household MW oven on the structural, compositional, morphological and textural characteristics of the produced HKUST-1 material and thereby on its performance in liquid phase adsorption [32].

This work presents an attempt to combine the "power" of MW-assisted synthesis and advantages of ILs as reaction media for the efficient control and improvement of the morphological and textural characteristics of the produced HKUST-1 material and thereby its behavior in methane and ethane adsorption. For this purpose, HKUST-1 materials were synthesized in ionic liquids via both MW technique and solvothermal procedure. Available alkylmethylimidazolium ILs with different alkyl groups, with triflate $\mathrm{CF}_{3} \mathrm{SO}_{3}{ }^{-}$ $\left(\mathrm{OTf}^{-}\right)$and bis(trifluoromethylsulfonyl)imide $\left(\mathrm{CF}_{3} \mathrm{SO}_{2}\right)_{2} \mathrm{~N}^{-}\left(\mathrm{Tf}_{2} \mathrm{~N}^{-}\right)$anions, were chosen as IL components in order to probe the alkyl chain effect on the properties of the formed MOF materials. The anion choice was dictated by thermal stability and reactivity. ILs with halogen or carboxylate anions are not thermally stable enough, while inorganic fluorinated complex anions such as $\mathrm{BF}_{4}{ }^{-}$or $\mathrm{PF}_{6}{ }^{-}$may be prone to decomposition in the presence of metal ions involved in MOF synthesis with the formation of metal fluorides at an elevated temperature.

The HKUST-1 materials synthesized in an IL medium under MW and solvothermal conditions were comparatively studied in methane and ethane adsorption at low and elevated pressures. To the best of our knowledge, there are no publications on high-pressure ethane adsorption. Therefore, we report, for the first time, the data on the high-pressure (>20 bar) adsorption of ethane for the HKUST-1 material.

\section{Materials and Methods}

The main reagents, i.e., 1-ethyl-3-methylimidazolium chloride, 1-methylimidazole, n-butyl chloride, n-octyl chloride, benzene-1,3,5-tricarboxylic acid $\left(\mathrm{H}_{3} \mathrm{btc}\right)$, copper nitrate trihydrate, copper acetate monohydrate and lithium bis(trifluoromethylsulfonyl)imide, are commercial products (Acros). All solvents were purified via common methods before use.

\subsection{Synthesis of Ionic Liquids}

1-Butyl-3-methylimidazolium triflate (BMIM OTf), 1-octyl-3-methylimidazolium triflate (OMIM OTf) and 1-ethyl-3-methylimidazolium bis(trifluoromethylsulfonyl)imide $\left(\mathrm{EMIM} \mathrm{Tf}_{2} \mathrm{~N}\right)$ were synthesized via well-known procedures with slight modification [38]. $\mathrm{BMIMCl}$ and $\mathrm{OMIMCl}$ were prepared by alkylation of 1-methylimidazole with corresponding alkyl chlorides in acetonitrile. ILs with the triflate anion were synthesized by ion exchange from the corresponding alkylmethylimidazolium chlorides and potassium triflate in acetonitrile. Then, the crude products were dissolved in $\mathrm{CH}_{2} \mathrm{Cl}_{2}$, and the halide impurities were extracted with water until a negative reaction with silver nitrate was noted. The 
EMIMTf $_{2} \mathrm{~N}$ was prepared via ion exchange with lithium bis(trifluoromethylsulfonyl)imide in water- $\mathrm{CH}_{2} \mathrm{Cl}_{2}$ mixture. All obtained ionic liquids were dried in a vacuum at $80{ }^{\circ} \mathrm{C}$ for $6 \mathrm{~h}$. The detailed procedures are provided in supplementary materials.

\subsection{Synthesis of HKUST-1 Materials}

Sample mw1 was synthesized according to the procedure reported in [32].

Sample solv1 was synthesized according to the procedure reported in [32].

Samples 3-8 were synthesized in IL media by a solvothermal method and in MW fields according to original procedures. Furthermore, when using ILs as a non-boiling solvent, it is crucial to effectively stir the reaction mixture to achieve homogenization of the reactant concentrations in the reaction volume.

The reagents $\left(\mathrm{H}_{3} \mathrm{btc}\right.$ and $\mathrm{Cu}^{2+}$ source) were preliminarily thoroughly ground in an agate mortar. The exact amounts of reagents, type of solvent, reaction conditions and yields are presented in Table 1.

Table 1. Synthesis of the HKUST-1 samples.

\begin{tabular}{|c|c|c|c|c|c|}
\hline \multirow[b]{2}{*}{ Material } & \multirow[b]{2}{*}{ Conditions } & \multicolumn{3}{|c|}{ Reaction Mixture Composition } & \multirow[b]{2}{*}{ Yield } \\
\hline & & $\mathrm{Cu}^{2+}$ Source & $\mathrm{H}_{3}$ btc & Solvent & \\
\hline 1solv [32] & $\begin{array}{l}\text { Solvothermal, } \\
10 \mathrm{~h}, 100^{\circ} \mathrm{C}\end{array}$ & $\begin{array}{c}\mathrm{Cu}\left(\mathrm{NO}_{3}\right)_{2} \cdot 3 \mathrm{H}_{2} \mathrm{O} \\
2 \mathrm{~g}, 8.58 \mathrm{mmol}\end{array}$ & $1 \mathrm{~g}, 4.7 \mathrm{mmol}$ & $\begin{array}{c}\mathrm{DMF}: \mathrm{H}_{2} \mathrm{O} \\
: \mathrm{EtOH}= \\
1: 1: 1, \text { total volume - } \\
45 \mathrm{~mL}\end{array}$ & $1.187 \mathrm{~g}, 83 \%$ \\
\hline 2solv & $\begin{array}{l}\text { Solvothermal, } \\
24 \mathrm{~h}, 130^{\circ} \mathrm{C}\end{array}$ & $\begin{array}{l}\mathrm{Cu}\left(\mathrm{NO}_{3}\right)_{2} \cdot 3 \mathrm{H}_{2} \mathrm{O}, \\
1 \mathrm{~g}, 3 \mathrm{~g}, 15 \mathrm{mmol}\end{array}$ & $1.5 \mathrm{~g}, 7 \mathrm{mmol}$ & $\begin{array}{c}\text { EMIM Tf }_{2} \mathrm{~N} \\
5 \mathrm{~mL}\end{array}$ & $0.86 \mathrm{~g}, 40 \%$ \\
\hline 3 solv & $\begin{array}{l}\text { Solvothermal, } \\
24 \mathrm{~h}, 130^{\circ} \mathrm{C}\end{array}$ & $\begin{array}{l}\mathrm{Cu}\left(\mathrm{NO}_{3}\right)_{2} \cdot 3 \mathrm{H}_{2} \mathrm{O}, \\
1 \mathrm{~g}, 3 \mathrm{~g}, 15 \mathrm{mmol}\end{array}$ & $1.5 \mathrm{~g}, 7 \mathrm{mmol}$ & $\begin{array}{l}\text { OMIM OTf, } \\
5 \mathrm{~mL}\end{array}$ & $1.17 \mathrm{~g}, 54 \%$ \\
\hline 8solv & $\begin{array}{l}\text { Solvothermal, } \\
24 \mathrm{~h}, 130^{\circ} \mathrm{C}\end{array}$ & $\begin{array}{c}\mathrm{Cu}\left(\mathrm{NO}_{3}\right)_{2} \cdot 3 \mathrm{H}_{2} \mathrm{O}, \\
1.2 \mathrm{~g}, 4.9 \mathrm{mmol}\end{array}$ & $\begin{array}{c}0.6 \mathrm{~g}, 2.8 \\
\mathrm{mmol}\end{array}$ & $\begin{array}{l}\text { BMIM OTF, } \\
10 \mathrm{~mL}\end{array}$ & $0.86 \mathrm{~g}, 99 \%$ \\
\hline $1 \mathrm{mw}$ [32] & $\mathrm{MW}, 30 \mathrm{~min}$ & $\begin{array}{c}\mathrm{Cu}\left(\mathrm{NO}_{3}\right)_{2} \cdot 3 \mathrm{H}_{2} \mathrm{O} \\
2 \mathrm{~g}, 8.58 \mathrm{mmol}\end{array}$ & $1 \mathrm{~g}, 4.7 \mathrm{mmol}$ & $\begin{array}{c}\mathrm{DMF}: \mathrm{H}_{2} \mathrm{O} \\
1: 1, \text { total volume - } \\
40 \mathrm{~mL}\end{array}$ & $\begin{array}{l}1.121 \mathrm{~g}, 79 \% \\
\text { [Molecules, } \\
2020]\end{array}$ \\
\hline $4 \mathrm{mw}$ & MW, $2 \mathrm{~min}$ & $\begin{array}{l}\mathrm{Cu}\left(\mathrm{NO}_{3}\right)_{2} \cdot 3 \mathrm{H}_{2} \mathrm{O} \\
1 \mathrm{~g}, 4 \mathrm{mmol}\end{array}$ & $\begin{array}{c}0.5 \mathrm{~g}, 2.3 \\
\mathrm{mmol}\end{array}$ & $\begin{array}{l}\text { BMIM OTF, } \\
5 \mathrm{~mL}\end{array}$ & $0.26 \mathrm{~g}, 70 \%$ \\
\hline $5 \mathrm{mw}$ & MW, $3 \mathrm{~min}$ & $\begin{array}{c}\mathrm{Cu}\left(\mathrm{NO}_{3}\right)_{2} \cdot 3 \mathrm{H}_{2} \mathrm{O}, \\
1.2 \mathrm{~g}, 4.9 \mathrm{mmol}\end{array}$ & $\begin{array}{l}0.6 \mathrm{~g}, 2.8 \\
\mathrm{mmol}\end{array}$ & OMIM OTF, $10 \mathrm{~mL}$ & $0.75 \mathrm{~g}, 90 \%$ \\
\hline $6 \mathrm{mw}$ & MW, $7 \mathrm{~min}$ & $\begin{array}{c}\mathrm{Cu}\left(\mathrm{NO}_{3}\right)_{2} \cdot 3 \mathrm{H}_{2} \mathrm{O}, \\
3.6 \mathrm{~g}, 18 \mathrm{mmol}\end{array}$ & $\begin{array}{c}1.68 \mathrm{~g}, 8 \\
\mathrm{mmol}\end{array}$ & $\begin{array}{l}\text { BMIM OTF, } \\
5 \mathrm{~mL}\end{array}$ & $2.1 \mathrm{~g}, 87 \%$ \\
\hline $7 \mathrm{mw}$ & MW, $5 \mathrm{~min}$ & $\begin{array}{c}\mathrm{Cu}\left(\mathrm{NO}_{3}\right)_{2} \cdot 3 \mathrm{H}_{2} \mathrm{O}, \\
3.63 \mathrm{~g}, 15 \mathrm{mmol}\end{array}$ & $\begin{array}{l}2.1 \mathrm{~g}, 10 \\
\mathrm{mmol}\end{array}$ & $\begin{array}{l}\text { EMIM Tf } 2 \mathrm{~N}, \\
5 \mathrm{~mL}\end{array}$ & $2.1 \mathrm{~g}, 70 \%$ \\
\hline
\end{tabular}

A conventional household inverter microwave oven Panasonic NN-GD366M with the standard frequency of $2450 \mathrm{MHz}$ was used for microwave-assisted syntheses at a power setting of $200 \mathrm{~W}$. The upper level of the liquid inside the glass reactor was $3 \mathrm{~cm}$ lower than the upper plane of the oven camera. The temperature of the solution was measured with a thermocouple immediately after turning off the microwave irradiation to prevent temperature measurement error.

Each reagent was mixed with $\frac{1}{2}$ of a necessary volume of the selected solvent, and then the mixtures were combined in the reaction tube. The reaction mixture was stirred during microwave irradiation with a glass overhead stirrer. The exact reaction times are presented in Table 1.

The reaction mixture (both after solvothermal and MW syntheses) was diluted with ethanol ( $\sim 20 \mathrm{~mL})$. The product was separated by centrifugation and thoroughly washed with ethanol $(3 \times 30 \mathrm{~mL})$. The obtained crystalline product was dried under a vacuum (RT, $2 \mathrm{~h}$ and $140^{\circ} \mathrm{C}, 6 \mathrm{~h}$ ).

To study the recyclability of ILs, the reaction mixture was diluted with ethanol after MW-synthesis, and the HKUST-1 product was centrifuged; the supernatant was collected and then rotary evaporated to remove ethanol. The residue was analyzed via NMR. 


\subsection{Material Characterization}

The microstructure and morphology of the synthesized samples were studied by field emission scanning electron microscopy (FE SEM) with a Hitachi SU8000 field-emission instrument. The target-oriented approach was utilized for the optimization of the analytical measurements [38]. The images were recorded in the secondary electron mode at an accelerating voltage of $2 \mathrm{kV}$ and a working distance of 5-6 mm. The morphology of the samples was studied with a correction applied to the surface effects of conduction layer sputtering. X-ray powder diffraction data were collected in a reflection mode using an EMPYREAN instrument (PANalytical, Malvern, UK) equipped with a linear $X^{\prime}$ celerator detector and non-monochromated $\mathrm{Cu} K \alpha$ radiation $(\alpha=1.5418 \AA)$, measurement parameters: tube voltage/current $40 \mathrm{kV} / 35 \mathrm{~mA}$, divergence slits of $1 / 8$ and $1 / 4^{\circ}, 2 \theta$ range $4-40^{\circ}$, speed $0.2^{\circ} \mathrm{min}^{-1}$. Porous structure characteristics of the synthesized materials were obtained using a standard adsorption isotherm of $\mathrm{N}_{2}$ at $77 \mathrm{~K}$ measured using ASAP 2020 Plus instrument (Micromeritics). The specific surface area (BET) was calculated from the adsorption data over the relative pressure range between 0.05 and 0.20 . The total pore volume $\left(\mathrm{V}_{\Sigma}\right)$ was evaluated at $p / p^{o}=0.95$, taking into account the asymptotic behavior of the isotherm at relative pressures approaching 1 . The thickness of the adsorbed multilayer generally appears to increase without limit when $p / p^{o}=1$. The cumulative volume at adsorption in the BJH method was taken as a mesopore volume $\left(\mathrm{V}_{\text {meso }}\right)$.

${ }^{1} \mathrm{H}$ NMR spectra were recorded using a Bruker AM300 instrument at a frequency of $300 \mathrm{MHz}$ using deuterated DMSO-d 6 .

Thermogravimetric analysis was performed using a Derivatograph- $\mathrm{C}$ instrument (MOM Company, Budapest, Hungary). Diffuse-reflectance infrared Fourier-transform spectra (DRIFTS) were recorded at room temperature with a Nicolet 460 Protégé spectrometer equipped with a diffuse-reflectance attachment. The samples were placed in the ampoules with a $\mathrm{KBr}$ window. The $\mathrm{CaF}_{2}$ powder was used as a standard. For a satisfactory signal-to-noise ratio, 500 spectra were collected. The spectra were measured at ambient temperature in the range of $6000-750 \mathrm{~cm}^{-1}$ in $4 \mathrm{~cm}^{-1}$ steps. The IR spectra of ionic liquids (OMIM OTf and EMIM Tf ${ }_{2} \mathrm{~N}$ ) were collected with the same spectrometer in a transmission mode. The KF glass slide was used as a standard.

\subsection{Gas Adsorption Experiments}

Adsorption of methane and ethane was studied in a classic Sieverts-type apparatus [39]. Adsorption was calculated from pressure measurements over 12-16 points using high precision empirical equations of state for each gas $[40,41]$. The parameters of the equations of states and other experimental details are provided in the supplementary information. Before measurements, the samples were evacuated at $140^{\circ} \mathrm{C}$ directly in the setup for $4 \mathrm{~h}$. The typical sample weight was $0.3-0.6 \mathrm{~g}$; the volume of samples was measured via helium pycnometry at room temperature.

\section{Results}

\subsection{Synthesis of HKUST-1 Material in the IL Medium}

In order to optimize the reaction time, the heating rates of selected ionic liquids and the DMF-water $(v / v)=1: 1$ system as reaction media under MW radiation were evaluated (Figure S1 in the Supplementary Materials). Figure S1 show clearly that the heating rate of the BMIM OTf is rather constant along with a temperature increase until $300{ }^{\circ} \mathrm{C}$, while the DMF-water mixture can be heated up to its boiling point $\left(104{ }^{\circ} \mathrm{C}\right)$. The IL heating rate is much higher than that of the DMF-water system due to the ionic conductivity and lower heat capacity of the IL. Therefore, using ILs as solvent systems, the reaction time was decreased to $5 \mathrm{~min}$ to prevent possible overheating of the reaction mixture and the formation of impurity phases.

The effect of the synthesis time on the yield of the HKUST-1 material was evaluated. Figure S2 show the linear increase in the HKUST-1 yield along with time with a maximum of $\sim 3$ min under MW radiation. Prolonged heating leads to lower HKUST-1 yields (70\% at 
$7 \mathrm{~min})$. After $7 \mathrm{~min}$ of heating, the color of the reaction mixture turns from dark blue to black. However, after cooling to room temperature and diluting the reaction mixture with ethanol $(20 \mathrm{~mL})$, the color of the suspension soon turns back to dark blue.

Efficient utilization of ILs (as a reaction medium) dictates increasing concentrations of the reagents for HKUST-1 synthesis as compared to its synthesis in common solvents (e.g., 1solv sample) due to the rather higher cost of IL. It was found that the optimal IL solvent quantity (independently of its kind) in the reaction mixture was $10 \mathrm{~mL}$.

A further increase in the volume of IL to $10 \mathrm{~mL}$ (Table 2, $5 \mathrm{mw}$ sample) led to an almost quantitative yield (99\%). Therefore, the fast (3 min) synthesis of HKUST-1 proceeds in an economical way in terms of the solvent:reagents ratio, i.e., over $1 \mathrm{~mol}$ of reactants per $1 \mathrm{~L}$ of the solvent. Therefore, the optimal conditions for the HKUST-1 material synthesis in ILs are those described for the $5 \mathrm{mw}$ sample.

Table 2. Textural properties and particle size of the synthesized HKUST-1 materials.

\begin{tabular}{|c|c|c|c|c|c|c|c|c|}
\hline Material & IL & $\begin{array}{l}\text { Heating } \\
\text { Method }\end{array}$ & $\begin{array}{c}\mathrm{A}_{\mathrm{BET}}(\mathrm{ISO}), * \\
\mathrm{~m}^{2} / \mathrm{g}\end{array}$ & $\begin{array}{l}\mathrm{V}_{\text {total, }}{ }^{\mathrm{a}} \\
\mathrm{cm}^{3} / \mathrm{g}\end{array}$ & $\begin{array}{c}\mathrm{V}_{\text {micro, }}{ }^{\mathrm{c}} \\
\mathrm{cm}^{3} / \mathrm{g}\end{array}$ & $\begin{array}{c}V_{\text {meso, }} b \\
\mathrm{~cm}^{3} / \mathrm{g}\end{array}$ & $\begin{array}{c}\text { Pore Width, } \\
\text { nm }\end{array}$ & Particle Size \\
\hline 1solv [32] & - & Solv & 1648 & 0.816 & 0.714 & 0.102 & $0.6-0.9$ & $8 \mu \mathrm{m}$ \\
\hline 2solv & EMIM $\mathrm{Tf}_{2} \mathrm{~N}$ & Solv & 497 & 0.274 & 0.230 & 0.044 & $0.6-0.9$ & $340 \mathrm{~nm}$ \\
\hline 3solv & OMIM OTf & Solv & 530 & 0.285 & 0.247 & 0.038 & $0.6-0.9$ & $\sim 1 \mu \mathrm{m}$ \\
\hline 2solv-after-rinsing & EMIM Tf $f_{2} \mathrm{~N}$ & Solv & 1158 & 0.560 & 0.424 & 0.136 & $0.6-1.0$ & $720 \mathrm{~nm}$ \\
\hline 3solv-after-rinsing & OMIM OTf & Solv & 1246 & 0.574 & 0.458 & 0.116 & $0.65-1.0$ & $870 \mathrm{~nm}$ \\
\hline 8solv & BMIM OTf & Solv & 1701 & 0.753 & 0.637 & 0.116 & $0.6-0.9$ & $350 \mathrm{~nm}$ \\
\hline $\mathbf{1 m w}$ [32] & - & MW & 2050 & 0.836 & 0.777 & 0.059 & $0.4-0.8$ & $25 \mu \mathrm{m}$ \\
\hline $4 \mathrm{mw}$ & BMIM OTf & MW & 1430 & 0.676 & 0.528 & 0.148 & $0.6-0.9$ & $200 \mathrm{~nm}$ \\
\hline $5 \mathrm{mw}$ & OMIM OTf & MW & 1782 & 0.759 & 0.680 & 0.079 & $0.6-0.9$ & $290 \mathrm{~nm}$ \\
\hline $6 \mathrm{mw}$ & BMIM OTf & MW & 818 & 0.416 & 0.330 & 0.086 & $0.6-0.9$ & $790 \mathrm{~nm}$ \\
\hline $7 \mathrm{mw}$ & EMIM $\mathrm{Tf}_{2} \mathrm{~N}$ & MW & 1772 & 0.766 & 0.680 & 0.064 & $0.6-0.9$ & $250-400 \mathrm{~nm}$ \\
\hline
\end{tabular}

${ }^{*}$ ISO 9277. ${ }^{\mathrm{a}} \mathrm{V}_{\text {total }}$ was estimated from the adsorption value at $p / p_{0}=0.99 ;{ }^{\mathrm{b}} V_{\mu}=V_{\Sigma}-V_{\text {meso }} .{ }^{\mathrm{c}}$ The cumulative mesopore volume was calculated at $2 \mathrm{~nm}$ from the desorption branch of the isotherm by the BJH method and the standard thickness of the adsorption film.

The 3solv and 2solv samples were prepared under solvothermal conditions using $5 \mathrm{~mL}$ of IL per $7 \mathrm{mmol}$ of $\mathrm{H}_{3}$ btc with yields of $40-50 \%$, correspondingly. In more dilute systems (8solv sample), a HKUST-1 yield as high as $99 \%$ was achieved.

According to elemental analysis data (Table S1 in the Supplementary Materials), the synthesized HKUST-1 samples contain only trace amounts of ILs, except for 2 solv and 3solv samples before extra-rinsing. Fluorine and nitrogen contents in these materials allow one to evaluate the presence of ILs cations and anions, correspondingly. In the 3solv and 2solv samples, the HKUST-1 matrix contains more anions than cations. However, extra-rinsing with DMF allows one to remove ILs almost completely from these materials affording 2solv-after-rinsing and 3solv-after-rinsing samples.

One of the main advantages of ILs over traditional organic solvents is the ease of purification via rotary evaporation due to the fact that ionic liquids are non-volatile. After the synthesis of sample $5 \mathrm{mw}$ under microwave conditions, the recyclability of the ionic liquid, e.g., OMIMOTf, was studied. Figure S3 show the comparison between the spectra of neat IL OMIMOTf and the IL recovered after MW synthesis. As can be seen, both spectra are almost identical, with the exception of two peaks corresponding to traces of ethanol, indicating the high thermal stability of IL under harsh synthesis conditions (microwave irradiation associated with a high temperature). Therefore, the proposed method allows one to easily reuse ionic liquids as the reaction media.

\subsection{XRD Analysis of the HKUST-1 Material}

The efficiency of the synthesis method was further justified by XRD data.

Powder diffraction patterns of all samples prove the presence of the HKUST-1 crystalline phase as the main phase.

A comparison of XRD patterns of the samples HKUST-1 $\mathbf{1}_{\text {DMF-MW }}$ synthesized by the MW technique in DMF as a unique solvent and 1mw (Figure S4) clearly show discrep- 
ancies in the relative heights of small-angle peaks, thus indicating the differences in the content of the voids in both samples. The Pawley fitting also led to slightly different values of the cubic unit cell parameter $a$ in HKUST-1 DMF-MW and 1mw - 26.292(5) and 26.321(5) $\AA$, respectively.

Note that the mixed solvent system, i.e., $\mathrm{DMF}-\mathrm{H}_{2} \mathrm{O}$, was selected in order to carry out this reaction in a more "green" way by reducing the content of toxic and rather expensive DMF in the synthesis medium.

Three samples, $\mathbf{5 m w}, \mathbf{7 m w}$ and $\mathbf{8 s o l v}$, synthesized in pure ILs, demonstrate no extra peaks from any additional phases (Figure 1).

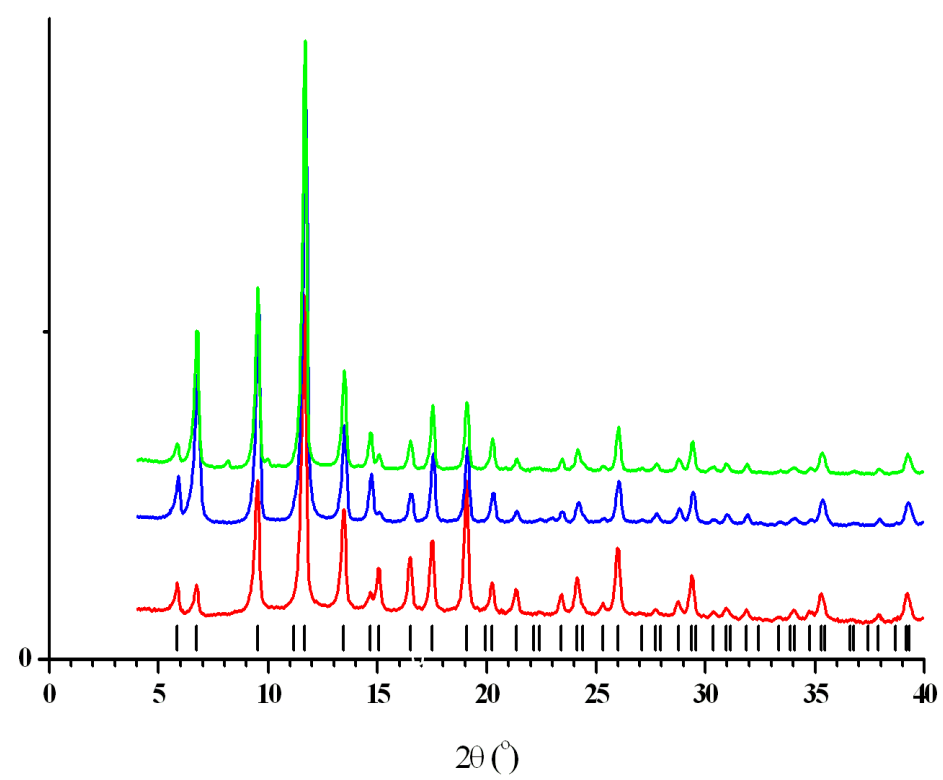

Figure 1. The combined presentation of the XRD patterns of the $5 \mathrm{mw}$ (red), $7 \mathbf{m w}$ (blue) and 8 solv (green) samples. The vertical black bars show the calculated peak positions of the cubic HKUST1 phase.

At the same time, the other samples are not single-phase materials. For example, the $3 s o l v$ material contains at least two additional crystalline phases. One of them is most probably copper oxalate hydrate with characteristic peaks at $2 \theta$ of 22.9 and $36.2^{\circ}$ (its content is about $10 \%$ ) and near $5 \%$ of unknown phase(s) with the peaks at 10.7, 12.6, 14.2, $27.4^{\circ}$ and some other $2 \theta$ angles (Figure S5).

Additional rinsing of the 3 solv sample, as a result of which 3solv-after-rinsing material was obtained, allowed one to reduce the content of the copper oxalate hydrate phase in the sample down to 3\% and completely remove unknown phase(s) (Figure S6).

Additional rinsing of the sample 2solv also did not lead to single-phase sample 2solvafter-rinsing, whose XRD pattern (Figure S7) contains characteristic peaks of two crystalline side phases, copper oxalate hydrate $\left(2 \theta 22.9^{\circ}\right)$ and copper nitrate hydroxide $(2 \theta 12.8,25.8$, $33.6^{\circ}$ ), with the total content of these side phases of about $4 \%$.

Coming back to single-phase samples, $5 \mathrm{mw}, 7 \mathbf{m w}$ and $\mathbf{8 s o l v}$, we should pay attention to the proximity of the values of their cubic unit cell parameter $a(26.313(2), 26.314(2)$ and 26.304(2) A, respectively) obtained in the Pawley fittings [42] performed with the program MRIA [43]. At the same time, it is worthy to note the essential difference in the heights of some low-angle peaks of $5 \mathrm{mw}$ (for example, at $2 \theta$ angles 6.8 and $15^{\circ}$, Figure 1 ) as compared with $\mathbf{7 m w}$ and 8solv. This difference is most probably related to the pore content, which, in turn, may impact the adsorption properties of these materials.

According to XRD results, the highest phase purity and crystallinity are observed for the samples 5mw and 8solv, synthesized in a more diluted IL solution using the same reaction mixture composition by MW and solvothermal technique, correspondingly. 
It could be suggested that the optimal synthesis time for the HKUST-1 material under MW activation conditions is $3 \mathrm{~min}$. Both synthesis time shortening ( $2 \mathrm{~min}$ ) and increasing $(7 \mathrm{~min}$ ) result in the appearance of additional peaks on the XRD pattern of the corresponding $4 \mathrm{mw}$ and $6 \mathrm{mw}$ samples. In this case, the effect of the reaction time is accompanied by the effect of the more concentrated reaction mixture.

By comparing the XRD data for $5 \mathrm{mw}, 7 \mathrm{mw}$ and 8 solv materials, it could be concluded that the reaction mixture composition, in particular, the IL content, has the dominating effect on the phase purity and crystallinity of the synthesized samples.

In order to study the possibility to produce the HKUST-1 material under scale-up conditions, it was synthesized using 10-fold quantities of the reagents as compared to the $1 \mathbf{m w}$ sample prepared using the MW technique in the DMF- $\mathrm{H}_{2} \mathrm{O}$ mixed solvent. XRD results (Figure S8) show that its structural characteristics are nearly identical to the structural characteristics of the $1 \mathrm{mw}$ sample.

To probe the stability of the HKUST-1 materials produced by different methods, the chemical stability of $1 \mathrm{mw}$ and $5 \mathrm{mw}$, along with 3 solv-after washing and 8solv materials, was studied by soaking them in water and methanol followed by the XRD measurements (Figures S9 and S10). It was found that these HKUST-1 samples produced by MW and solvothermal techniques retain their structural characteristics almost intact after contacting with these solvents $\left(4 \mathrm{~h}, 22^{\circ} \mathrm{C}\right)$.

These data confirmed the possibility of the practical implementation of the HKUST-1 based adsorbents synthesized by the described methods.

\subsection{Morphology of the HKUST-1 Materials}

The morphology of the synthesized HKUST-1 materials was studied by the SEM method. It was found that synthesis conditions, i.e., heating mode, solvent and reaction time, impact remarkably on the crystallite size. The $1 \mathbf{m w}$ material synthesized in MW fields in a DMF- $\mathrm{H}_{2} \mathrm{O}$ system shows the largest crystal size $(\sim 25 \mu \mathrm{m}$, Figure S11a) [32]. Note, the 1solv material obtained under solvothermal conditions in the DMF- $\mathrm{H}_{2} \mathrm{O}-\mathrm{EtOH}$ system is composed of smaller crystallites $(\sim 8 \mu \mathrm{m}$, Figure S11b). Probably, the crystal growth rate prevails over the rate of nucleation under conditions of MW radiation.

According to the literature data [29] and this work's results, microwave-assisted ionothermal synthesis is a more effective method for crystallization time shortening. The local superheating could facilitate the reagent conversion [21]. For instance, local superheating accelerated the crystallization of the ZIF-8 material under conditions of MW-assisted ionothermal synthesis [29].

Using IL as a synthesis medium results in particle size reduction both for solvothermal and MW samples. All materials synthesized in ILs are composed of crystallites with sizes varying in the range of $200-800 \mathrm{~nm}$. This IL effect could be explained by preventing crystal growth by IL interacting with HKUST-1 crystallization sites [32].

Probably, in the case of the usage ILs as reaction medium for the HKUST-1 synthesis, they can act as surfactants [44] and capping agents. Therefore, anions and cations in their structures can bind with $\mathrm{Cu}^{2+}$ open sites and btc linkers (coordinated partially) in HKUST-1 nanoparticles preventing crystal growth in this manner. In addition, $\mathrm{Cu}(\mathrm{II})$ complexes with IL anions, such as $\mathrm{Tf}_{2} \mathrm{~N}$ (which is a constituent of the 2 solv and $7 \mathbf{m w}$ samples), are reported in [45].

Again, the dominating factor for the phase purity of the synthesized HKUST-1 materials is the IL content in the reaction mixture. Therefore, the HKUST-1 particle size is almost the same for $5 \mathbf{m w}(\sim 290 \mathrm{~nm})$ (Figure 2a) and 8solv $(\sim 360 \mathrm{~nm})$ (Figure S12a) samples synthesized in a more diluted solution in MW fields and by the solvothermal technique. The 2solv-after-rinsing and 3solv-after-rinsing samples obtained in a more concentrated solution than the 8solv material have more than twice the crystallite size (Figure S12b,c). 


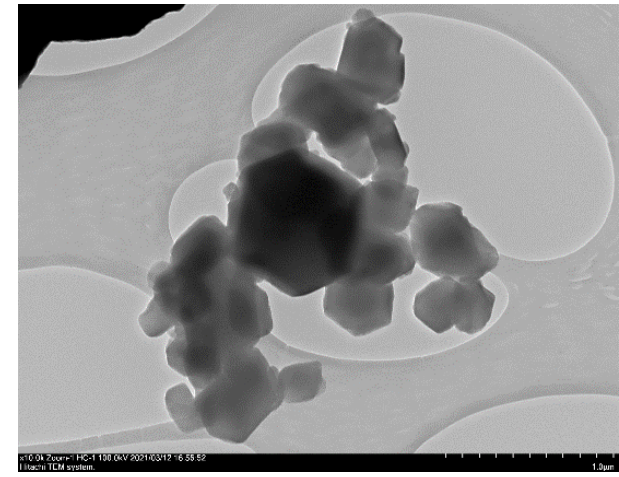

(a)

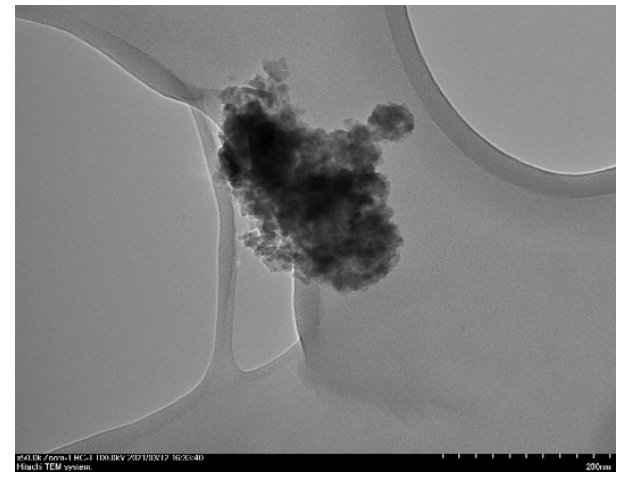

(b)

Figure 2. TEM images of $5 \mathrm{mw}(\mathrm{a})$ and $4 \mathrm{mw}(\mathrm{b})$ materials.

In the case of MW synthesis, the reaction time is an additional factor. Therefore, the $4 \mathrm{mw}$ sample synthesized using BMIMOTf in MW fields in the shortest time period ( 2 min) has the smallest particle size ( 200 nm) (Figure 2b)). Probably, for the MW synthesis, a reaction time as short as $2 \mathrm{~min}$ is crucial for the dramatic reduction of the HKUST- 1 crystal size. As a result, the $6 \mathrm{mw}$ material synthesized in the same IL (BMIMOTF) as the $4 \mathbf{m w}$ sample, but in a more concentrated reaction solution and for two-fold prolonged reaction time ( $5 \mathrm{~min}$ ), has around a three-fold larger crystal size- $750 \mathrm{~nm}$ (Figure S13a). The $7 \mathrm{mw}$ sample prepared with the same reaction time of $\sim 7 \mathrm{~min}$ and in the most concentrated reaction mixture as $6 \mathrm{mw}$ is composed of a smaller particle size (around $570 \mathrm{~nm}$, Figure S13b).

The comparison of the HKUST-1 materials synthesized in the IL medium by the MW technique and under solvothermal conditions clearly shows the differences in their morphology. Furthermore, the crystallite habit of the solvothermal samples (prepared within the same reaction time) depends on the IL nature. In particular, the 8solv sample obtained in BMIMOTF is composed of rather well-shaped distorted cubic crystals (Figure S12a). The 2solv-after-rinsing and 3solv-after-rinsing samples synthesized under solvothermal conditions using different ionic liquids, i.e., EMIMTf $_{2} \mathrm{~N}$ and OMIMOTf, respectively, are shaped as octahedra (2solv-after-rinsing) (Figure S12b) and rhombohedra (3solv-afterrinsing) (Figure S12c) after post-treatment with solvents.

In contrast, the $6 \mathrm{mw}$ and $7 \mathrm{mw}$ materials produced in MW fields using BMIMOTF and EMIMTf $_{2} \mathrm{~N}$, correspondingly, are composed of the crystallite concretions with an irregular shape (Figure S13a,b).

It can be suggested that the differences in the habit of the HKUST-1 materials synthesized by different activation methods in the IL medium may be related to the specific mechanisms of crystallization in MW fields and under solvothermal conditions.

\subsection{Textural Properties and Particle Size of the Synthesized HKUST-1 Materials}

The HKUST-1 samples differ remarkably in the specific surface area and pore volume depending on the synthesis mode (Table 2). According to XRD results, the synthesis method significantly affects the HKUST- 1 phase purity.

The 8solv material synthesized in a more diluted (twice) reaction mixture in the OMIMOTf medium has a specific surface area that is even larger than that of the 1solv material synthesized in the DMF- $\mathrm{H}_{2} \mathrm{O}$ system (Table 2). Moreover, the specific surface area of 8solv is even larger than that of the 1solv sample synthesized in the $\mathrm{EtOH}-\mathrm{H}_{2} \mathrm{O}$ system. On the contrary, its porosity is slightly decreased compared to the 1solv sample. However, the mesopore fractions in both 1solv and 8solv materials are rather similar.

According to elemental analysis data (Table S1), 2solv and 3solv materials synthesized in a concentrated reaction mixture contain around 8-10 wt. \% of IL. It is likely that IL used as a synthesis medium is located in the mesopores or intercrystalline space in these materials. Therefore, the specific surface area and pore volume of these samples are much smaller than these characteristics obtained for other synthesized HKUST-1 materials (Table 2). 
Additional treatment of the $\mathbf{2 s o l v}$ and 3solv samples with EtOH results in a remarkable increase of the specific surface area and porosity. Simultaneously, the mesopore content in the corresponding 2solv-after-rinsing and 3solv-after-rinsing materials increases.

The 2solv-after-rinsing and 3solv-after-rinsing samples show a lower surface areas, which is possibly due to the presence of IL residues entrapped in their pores. The 2 solvafter-rinsing sample has the highest mesopore content, and a reduced specific surface area among solvothermal HKUST-1 materials, probably due to the nature of IL $\left(\mathrm{EMIMTf}_{2} \mathrm{~N}\right)$ used as a solvent. This phenomenon could indicate that IL plays the role of the structuredirecting agent in the formation of the HKUST-1 matrix. A similar suggestion was made for the ionothermal synthesis of the zeolitic imidazolate framework ZIF-8 in the MW fields [29].

The $4 \mathrm{mw}$ material has a higher mesopore content and decreased surface area compared to its other counterparts. The decreased surface areas and porosity of $4 \mathbf{m w}$ and $6 \mathbf{m w}$ systems are probably related to the use of a more concentrated reaction solution leading to the presence of additional crystalline phases according to XRD results. Additionally, the mesopore content in the $4 \mathrm{mw}$ material could probably be attributed to its small particle size ( 200 nm).

The heating mode does not remarkably impact the textural properties of the produced HKUST-1 material. Therefore, the $5 \mathbf{m w}, 7 \mathbf{m w}$ and $\mathbf{8 s o l v}$ samples have specific surface areas comparable with the best HKUST-1 samples reported to date, such as the HKUST-1 material synthesized in the DMF- $\mathrm{H}_{2} \mathrm{O}$ system in MW fields with the highest surface area [32].

In particular, $5 \mathrm{mw}$ and $7 \mathrm{mw}$ materials synthesized in OMIMOTf and EMIMTf $2 \mathrm{~N}$, respectively, have almost the same specific surface area (BET) and porosity, which are highest among HKUST-1 materials obtained in ILs (Table 2).

In spite of differences in the specific surface area and pore volume, HKUST-1 materials synthesized in IL media show almost a similar micropore width (Table 2).

\subsection{Thermal Stability of the HKUST-1 Materials}

The thermal stability of representative HKUST-1 materials obtained by changing synthesis variables, $\mathbf{1 m w}, \mathbf{5 m w}, \mathbf{7 m w}$ and $\mathbf{8 s o l v}$ samples was probed by the TGA method. The results of this study (Figure S14) show that all samples maintain network integrity until 320-330 ${ }^{\circ} \mathrm{C}$. However, the mass loss could be associated with different pore content in the studied HKUST-1 materials. This observation is in accordance with XRD data (Section 3.2). The solvent residues may be responsible for the differences in mass loss of the studied HKUST-1 materials under TGA measurements. These results confirm the stability of the HKUST-1 materials during their preparation at elevated temperatures under conditions of the MW-activation of the reaction mass.

\subsection{DRIFTS Study of the Synthesized HKUST-1 Materials}

Pore chemistry of the synthesized HKUST-1 materials was studied using the DRIFTS method (ESI). Note that the obtained results could indicate the absence of IL residues in the synthesized HKUST-1 (5mw, 7mw and 8solv) materials. Furthermore, the DRIFTS study revealed the absence of adsorbed or coordinated water in $5 \mathbf{m w}, 7 \mathbf{m w}$ and 8 solv samples.

\subsection{Adsorption Performance}

All adsorption isotherms measured for the synthesized HKUST-1 materials using pure $\mathrm{CH}_{4}$ and $\mathrm{C}_{2} \mathrm{H}_{6}$ exhibit type I shapes (Figures S21 and S22). Moreover, the methane adsorption isotherm for the 1solv sample synthesized in the DMF-water system is similar to the literature data [15]. The 1mw material produced in MW fields in the same mixed solvent shows rather similar adsorption properties as solvothermal one (Figure 3). 


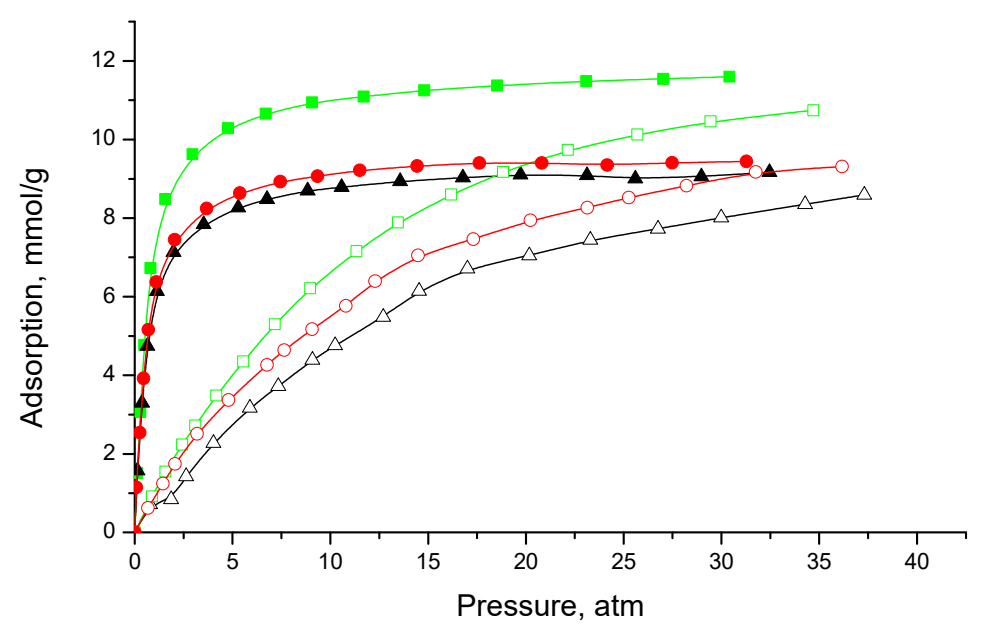

Figure 3. Adsorption isotherms for the $\mathbf{5 m w}(\square), \mathbf{1 m w}(\bullet)$ and $\mathbf{1 s o l v}(\mathbf{\Delta})$ materials at $298 \mathrm{~K}$. Hollow symbols—methane adsorption, solid symbols—ethane adsorption.

The results of the adsorption measurements for the synthesized HKUST-1 materials show that the main factors affecting their capacities are the specific surface area, pore volume and crystallite size. Furthermore, the combination of these factors is required for optimal performance. Therefore, the $5 \mathrm{mw}$ material with a high specific surface area and micropore volume associated with the small $(\sim 280 \mathrm{~nm})$ size of the crystallites demonstrates the best adsorption capacity for ethane and methane within the entire pressure range. According to Figure 3 and Table 3, the $5 \mathrm{mw}$ material exhibits $\sim 20 \%$ higher adsorption of methane and ethane than the samples synthesized in a $\mathrm{DMF}-\mathrm{H}_{2} \mathrm{O}$ medium $(\mathbf{1} \mathbf{m w}$ and 1solv). The maximum adsorption value for the sample $5 \mathrm{mw}$ is $11.4 \mathrm{mmol} / \mathrm{g}$ for ethane (at $20 \mathrm{~atm}$ ) and $9.37 \mathrm{mmol} / \mathrm{g}$ for methane (at $20 \mathrm{~atm}$ ).

Table 3. Adsorption capacities of synthesized HKUST-1 materials towards methane and ethane.

\begin{tabular}{|c|c|c|c|c|c|c|}
\hline Sample Code & $\begin{array}{c}\mathrm{a}\left(\mathrm{C}_{2} \mathrm{H}_{6}, 1 \mathrm{~atm}\right) \\
\mathrm{mmol} / \mathrm{g}\end{array}$ & $\begin{array}{c}\mathrm{a}\left(\mathrm{CH}_{4}, 1 \mathrm{~atm}\right) \\
\mathrm{mmol} / \mathrm{g}\end{array}$ & $\begin{array}{c}\mathrm{a}\left(\mathrm{C}_{2} \mathrm{H}_{6}, 5 \mathrm{~atm}\right) \\
\mathrm{mmol} / \mathrm{g}\end{array}$ & $\begin{array}{c}\mathrm{a}\left(\mathrm{CH}_{4}, 5 \mathrm{~atm}\right), \\
\mathrm{mmol} / \mathrm{g}\end{array}$ & $\begin{array}{c}\mathrm{a}\left(\mathrm{C}_{2} \mathrm{H}_{6}, 20 \mathrm{~atm}\right) \\
\mathrm{mmol} / \mathrm{g}\end{array}$ & $\begin{array}{c}\mathrm{a}\left(\mathrm{CH}_{4}, 20 \mathrm{~atm}\right), \\
\mathrm{mmol} / \mathrm{g}\end{array}$ \\
\hline 1solv & 5.74 & 0.74 & 8.1 & 2.75 & 9.12 & 7 \\
\hline $1 \mathrm{mw}$ & 6.1 & 0.82 & 8.5 & 3.48 & 9.4 & 7.93 \\
\hline 2 solv & 2.32 & 0.52 & 3.37 & 1.27 & 3.89 & 3.31 \\
\hline 3solv & 2.1 & 0.51 & 3.06 & 1.25 & 3.6 & 3.2 \\
\hline $\begin{array}{l}\text { 2solv-after- } \\
\text { rinsing }\end{array}$ & 3.72 & 0.8 & 5.18 & 2.60 & 6.02 & 5.54 \\
\hline $\begin{array}{l}\text { 3solv-after- } \\
\text { rinsing }\end{array}$ & 3.77 & 0.77 & 5.48 & 2.69 & 6.46 & 5.80 \\
\hline $4 \mathrm{mw}$ & 4.3 & 0.92 & 5.74 & 2.79 & 6.42 & 5.28 \\
\hline $5 \mathrm{mw}$ & 7.18 & 1.03 & 10.3 & 4 & 11.4 & 9.37 \\
\hline $6 \mathrm{mw}$ & 3.58 & 0.62 & 5.26 & 2.19 & 6.02 & 4.89 \\
\hline $7 \mathrm{mw}$ & 5.97 & 0.89 & 8.7 & 3.33 & 9.98 & 8 \\
\hline 8solv & 5.81 & 0.98 & 8.71 & 3.74 & 10 & 8.49 \\
\hline $\begin{array}{l}\text { HKUST-1 lit. } \\
\text { data }\end{array}$ & 3.5 [16] & 0.8 [15] & - & 2.9 [15] & - & 7.0 [15] \\
\hline
\end{tabular}

In particular, the methane adsorption value obtained for the $5 \mathrm{mw}$ material is almost identical to the methane capacity of best DUT-like adsorbents [12], such as DUT76 , i.e., $9.5 \mathrm{mmol} / \mathrm{g}(20 \mathrm{~atm})$. The adsorption capacities of 2 solv and 3 solv samples are markedly improved after extra-rinsing (Figure 4, Table 3), along with an increase in the specific surface area and porosity (2solv-after-rinsing and 3solv-after-rinsing samples) (Table 2). The $\mathbf{7} \mathbf{m w}$ and 8 solv samples posessing almost the same specific surface area and crystallite size (Table 2) show very close and high adsorption capacities both for methane 
and ethane, which are slightly inferior to the capacity measured for the $5 \mathrm{mw}$ material with a higher dispersion and smaller nanoparticle size (Table 3).

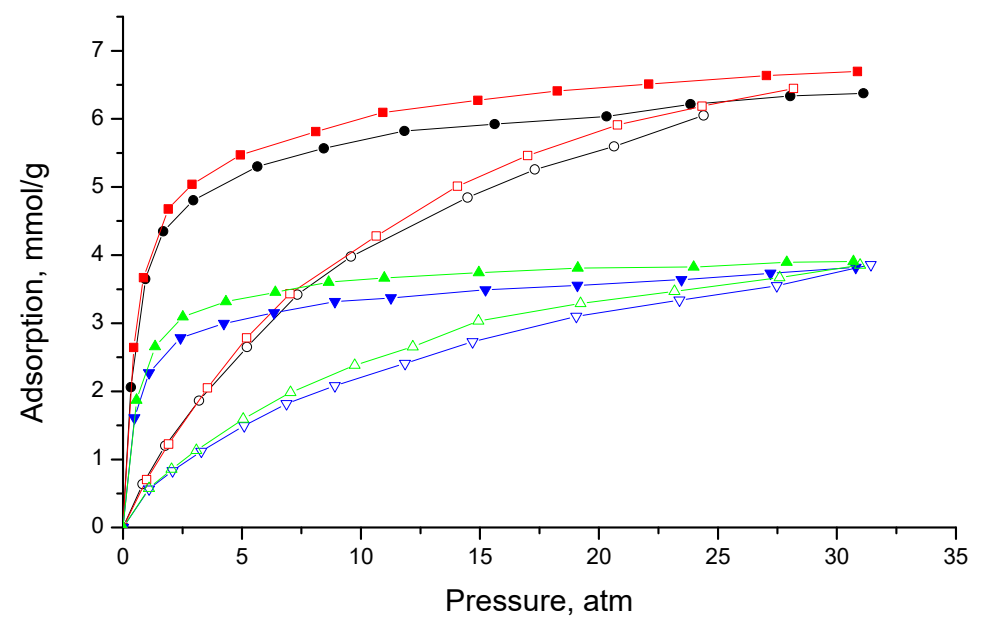

Figure 4. Adsorption isotherms for the samples $\mathbf{\nabla}-\mathbf{2 s o l v}, \mathbf{\Lambda}-\mathbf{3 s o l v}, \bullet-2$ solv-after-rinsing and 3solv-after-rinsing at $298 \mathrm{~K}$. Hollow symbols—methane adsorption, solid symbols—ethane adsorption.

On the other hand, the $4 \mathrm{mw}$ sample with the smallest particle size, but with the decreased specific surface area and porosity as compared with $5 \mathrm{mw}, 7 \mathbf{m w}$ and 8 solv materials (Table 2), is inferior to them concerning adsorption capacity (Table 3). A further decrease in the adsorption capacity (Table 3 ) is observed for $6 \mathbf{m w}$, 2 solv and 3solv materials with a lower specific surface area and micropore volume and relatively larger nanocrystallites (Table 2). Note that these textural and morphological characteristics are rather similar for the three mentioned samples.

In addition, the importance of the small HKUST-1 crystallite size for a good adsorption capacity is illustrated by an example of $\mathbf{1} \mathbf{m w}$ material with the highest specific surface area and porosity, but a very large crystal size, around $25 \mu \mathrm{m}$. This sample has a decreased adsorption capacity compared with the $5 \mathrm{mw}$ sample with lower specific surface area and porosity but a small nanocrystallite size (Tables 2 and 3).

The selectivity tendency follows some trends other than the adsorption capacity. To the best of our knowledge, the IAST and ideal selectivity values for the ethane/methane pair in a wide pressure range were reported for the HKUST-1 material for the first time (Figure 5).
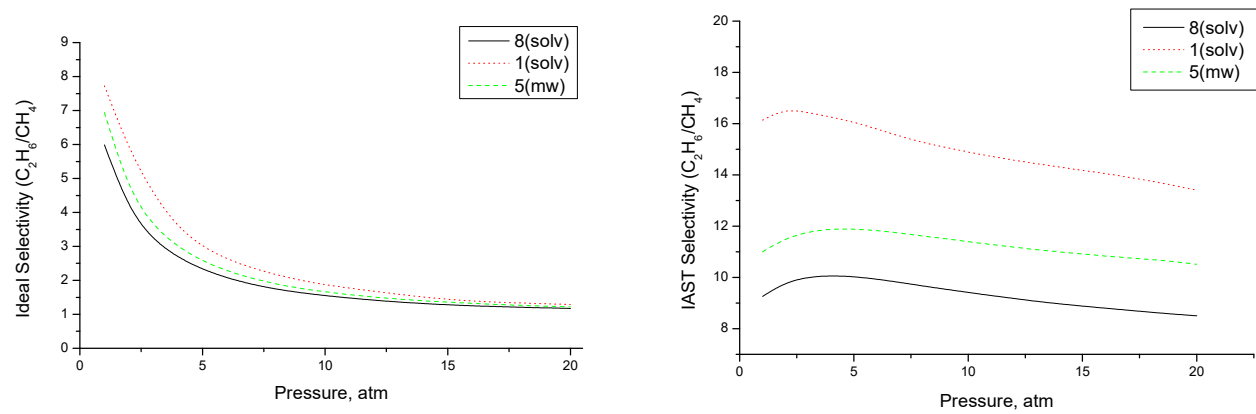

Figure 5. The pressure dependencies of $\mathrm{C}_{2} \mathrm{H}_{6} / \mathrm{CH}_{4}$ ideal and IAST selectivities at $298 \mathrm{~K}$ for the 1solv, $5 \mathrm{mw}$ and 8solv samples.

The best ideal selectivity ratio for $\mathrm{C}_{2} \mathrm{H}_{6}: \mathrm{CH}_{4}$ was obtained on the 1solv sample (Table 4). It should be noted that currently, there are no available literature data on the ideal selectivity of adsorption of methane and ethane on HKUST-1. Thus, we have calculated the ideal selectivity for the ethane/methane pair based on the data from works $[15,16]$. At 
1 bar and $298 \mathrm{~K}$, the calculated value of the ideal selectivity for $\mathrm{C}_{2} \mathrm{H}_{6} / \mathrm{CH}_{4}$ was 4.375 . It should be noted that this value can serve for comparison purposes only because it was obtained on two different samples and from different experiments. Nevertheless, the ideal selectivity value obtained for the 1 solv material is 7.76 at $1 \mathrm{~atm}$, which is noticeably higher than that reported in $[15,16]$.

Table 4. Ideal selectivity for methane and ethane for obtained samples of HKUST-1.

\begin{tabular}{|c|c|c|c|c|c|c|}
\hline \multirow[b]{2}{*}{ Sample Code } & \multicolumn{3}{|c|}{ Ideal Selectivity * } & \multicolumn{3}{|c|}{ IAST Selectivity at $y\left(\mathrm{CH}_{4}\right)=0.9$} \\
\hline & $\begin{array}{c}\mathrm{C}_{2} \mathrm{H}_{6}: \mathrm{CH}_{4} \text { at } \\
\mathrm{P}=1 \mathrm{~atm}\end{array}$ & $\begin{array}{c}\mathrm{C}_{2} \mathrm{H}_{6}: \mathrm{CH}_{4} \text { at } \\
P=5 \mathrm{~atm}\end{array}$ & $\begin{array}{c}\mathrm{C}_{2} \mathrm{H}_{6}: \mathrm{CH}_{4} \text { at } \\
P=20 \mathrm{~atm}\end{array}$ & $\begin{array}{c}\mathrm{C}_{2} \mathrm{H}_{6}: \mathrm{CH}_{4} \text { at } \\
\mathrm{P}=1 \mathrm{~atm}\end{array}$ & $\begin{array}{c}\mathrm{C}_{2} \mathrm{H}_{6}: \mathrm{CH}_{4} \text { at } \\
\mathrm{P}=5 \mathrm{~atm}\end{array}$ & $\begin{array}{c}\mathrm{C}_{2} \mathrm{H}_{6}: \mathrm{CH}_{4} \text { at } \\
\mathrm{P}=20 \mathrm{~atm}\end{array}$ \\
\hline 1solv & 7.76 & 2.95 & 1.30 & 16.13 & 16.05 & 13.40 \\
\hline $1 \mathrm{mw}$ & 7.44 & 2.44 & 1.19 & 12.28 & 12.51 & 10.64 \\
\hline 2 solv & 3.56 & 2.10 & 1.15 & 7.71 & 8.67 & 7.36 \\
\hline 3solv & 3.75 & 2.09 & 1.18 & 4.84 & 7.29 & 6.90 \\
\hline $\begin{array}{l}\text { 2solv-after- } \\
\text { rinsing }\end{array}$ & 4.88 & 2.01 & 1.08 & 5.90 & 7.76 & 6.40 \\
\hline $\begin{array}{l}\text { 3solv-after- } \\
\text { rinsing }\end{array}$ & 5.39 & 2.03 & 1.09 & 5.45 & 7.83 & 6.69 \\
\hline $4 \mathrm{mw}$ & 4.67 & 2.06 & 1.22 & 6.49 & 8.97 & 8.71 \\
\hline $5 \mathrm{mw}$ & 6.97 & 2.58 & 1.22 & 11.0 & 11.89 & 10.51 \\
\hline $6 \mathrm{mw}$ & 5.77 & 2.40 & 1.23 & 9.61 & 10.13 & 8.30 \\
\hline $7 \mathrm{mw}$ & 6.71 & 2.61 & 1.25 & 9.82 & 11.01 & 9.6 \\
\hline 8solv & 5.93 & 2.33 & 1.18 & 9.30 & 10.05 & 8.51 \\
\hline
\end{tabular}

${ }^{*}$ Ideal selectivity was calculated as the ratio of adsorption values of methane and ethane at equal pressures $(1,5$, $20 \mathrm{~atm})$.

In the case of the $\mathbf{2 s o l v}$ material, the entrapped IL not only reduces the adsorption values but also has a remarkable impact on selectivity. Therefore, this sample shows similar adsorption values of methane and ethane at pressures of around $20 \mathrm{~atm}$ (Table 3).

In IAST calculations, the value for $y\left(\mathrm{CH}_{4}\right)=0.9$ was selected because ethane is the minor component of natural gas, with concentrations usually within $5-15 \%$. Note that the dependencies of the ideal selectivity exhibit a similar shape, asymptotically decreasing to unity at higher pressures. The IAST method, provides different dependencies. As shown in Figure 5, all HKUST-1 samples synthesized by various methods show a clear maximum in the pressure range from 3 to $5 \mathrm{~atm}$. The maximum value of the IAST selectivity for the 1solv material is around 16.5 for the ethane/methane pair.

The correlation of the obtained ideal selectivity with textural characteristics of the synthesized samples reveals that the ideal selectivity almost linearly increases with a gain in the $S_{\text {BET }}$ value $\left(R^{2}=0.85\right)$ (Figure 6a), while the correlation of the selectivity with the $V_{\text {micro }} / V_{\text {meso }}$ ratio was less clear $\left(R^{2}=0.62\right)$ (Figure $\left.6 \mathrm{~b}\right)$. It can be suggested that an "ideal" sample of HKUST-1 designed for methane and ethane separation should have as high as possible $S_{\mathrm{BET}}$ and a maximum fraction of micropores. Moreover, the average particle size has almost no impact on selectivity, which makes it very promising for industrial application because the use of adsorbents with larger particle sizes in certain cases should be more convenient from the practical point of view.

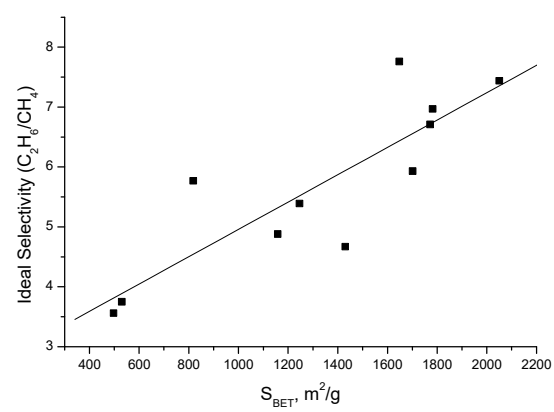

(a)

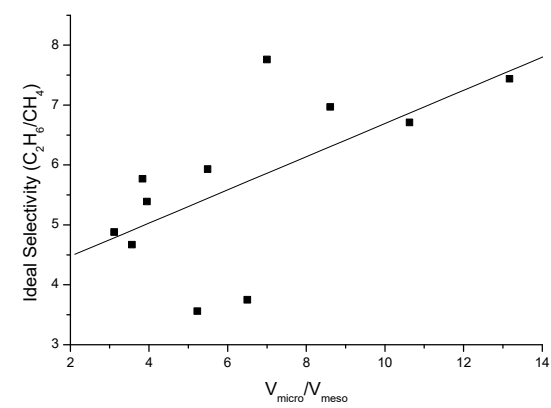

(b)

Figure 6. The correlation of the ideal selectivity of the synthesized HKUST-1 adsorbents for a $\mathrm{C}_{2} \mathrm{H}_{6} / \mathrm{CH}_{4}$ mixture with (a) $S_{\mathrm{BET}}$ and (b) $V_{\text {micro }} / V_{\text {meso }}$. 


\section{Conclusions}

A series of HKUST-1 materials were synthesized in an IL medium under solvothermal conditions and under MW activation. Using this kind of solvent system allows one to reduce the HKUST-1 crystallite size efficiently as compared to HKUST-1 materials synthesized both under solvothermal and MW conditions. It was found that synthesis variables, such as reaction time and IL content in the reaction mixture, dramatically influence the phase purity, crystallinity, crystallite size and textural properties of resulting HKUST-1 samples. Moreover, the used ILs appear to be stable under microwave conditions and may be separated and reused in the following experiments.

In particular, the HKUST-1 material prepared in ILs by the MW activation technique under optimized synthesis conditions features an enhanced adsorption capacity for ethane and methane. The achieved methane adsorption value for this material is comparable with the best adsorption capacities demonstrated by the best MOF adsorbents, e.g., DUT-76 MOF.

To the best of our knowledge, the IAST and ideal selectivity values for the ethane/ methane pair were reported for the HKUST-1 material for the first time in a wide pressure range. The correlation between the ideal selectivities of the synthesized HKUST-1 materials and their specific surface area (BET) and the ratio of micro:meso pore volumes was found. The adsorbent prepared in the DMF-water system under solvothermal conditions shows the best ideal selectivity (experimental and calculated by IAST).

The HKUST-1 samples synthesized in common solvent systems and ILs under solvothermal conditions and MW fields may serve as models for investigations of the factors influencing the adsorption behavior of the MOF materials. Therefore, the results of this work may contribute to the design of the adsorbents for ethane and methane based on HKUST-1 material as well as new MOFs.

Supplementary Materials: The following data are available online at https:/ /www.mdpi.com/ article/10.3390/cryst12020279/s1, Figure S1: Heating rates of [BMIM] OTf and water : DMF = 1 : 1 solvent systems in MW fields; Figure S2: Dependence of the yield of the HKUST-1 material on the reaction time under conditions of the MW-assisted synthesis; Figure S3: ${ }^{1} \mathrm{H}$ NMR spectra of the neat IL OMIM OTf and of the same IL recycled after synthesis; Figure S4: A comparison of

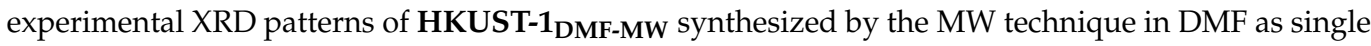
solvent and 1mw material; Figure S5: The experimental and calculated after the Pawley fitting XRD patterns of the 3solv sample; Figure S6: The experimental and calculated after the Pawley fitting XRD patterns of the sample 3solv-after-rinsing; Figure S7: The experimental and calculated after the Pawley fitting XRD patterns of the sample 2solv-after-rinsing; Figure S8: Experimental XRD pattern of HKUST-1 sample produced using tenfold quantities of the reagents; Figure S9: XRD patterns of 1mw, 8solv, 5mw and 7mw materials soaked in $\mathrm{MeOH}$; Figure S10: XRD patterns of 1mw, 8solv, $5 \mathbf{m w}$ and $7 \mathbf{m w}$ materials soaked in $\mathrm{H}_{2} \mathrm{O}$; Figure S11: SEM images of the $\mathbf{1} \mathbf{m w}$ and 1solv samples; Figure S12: SEM images of the 8solv, 2solv-after-rinsing and 3solv-after-rinsing samples; Figure S13: SEM images of the $\mathbf{6 m w}$ and $7 \mathbf{m w}$ samples; Figure S14: TG Curves of the $1 \mathbf{m w}$, 8 solv, $5 \mathrm{mw}$ and $7 \mathbf{m w}$ materials; Figure S15: DRIFT spectra of the 5mw sample and ionic liquid OMIM OTf in a wide range and $1800-750 \mathrm{~cm}^{-1}$ region; Figure S16: DRIFT spectra of the $7 \mathrm{mw}$ sample and ionic liquid EMIM $\mathrm{Tf}_{2} \mathrm{~N}$ in a wide range and $1800-750 \mathrm{~cm}^{-1}$ region; Figure S17: DRIFT spectra of $5 \mathbf{m w}$ (black), $7 \mathbf{m w}$ (red) and 8solv (green) samples; Figure S18: DRIFT spectra of $5 \mathbf{m w}, 7 \mathbf{m w}$ and 8 solv samples in the frequency range of $3800-2400 \mathrm{~cm}^{-1}$. Figure S19: DRIFT spectra of $5 \mathbf{m}, 7 \mathbf{m w}$ and 8 solv samples in the frequency range of $1800-750 \mathrm{~cm}^{-1}$. Figure S20: The schematic diagram of the adsorption setup; Figure S21: Methane adsorption isotherms for all obtained samples at $298 \mathrm{~K}$; Figure S22: Ethane adsorption isotherms for all obtained samples at $298 \mathrm{~K}$. Table S1: Elemental analysis data for the synthesized HKUST-1 materials.

Author Contributions: Conceptualization, G.S.D., L.M.G. and V.I.I.; methodology, V.V.V., D.A.A., G.S.D. and L.M.G.; software, V.V.C.; validation, L.M.G., G.S.D. and V.V.C.; formal analysis, G.I.K., O.P.T., V.D.N. and V.V.C.; investigation, V.V.V., D.A.A., G.S.D., L.M.G., G.I.K., O.P.T., V.D.N. and V.V.C.; resources, L.M.K.; data curation, V.I.I., G.S.D. and L.M.G.; writing-original draft preparation, G.S.D., L.M.G. and V.I.I.; writing-review and editing, L.M.K. and V.I.I.; visualization, V.V.C. and 
G.I.K.; supervision, L.M.K.; project administration, V.I.I. and L.M.K.; funding acquisition, L.M.K. and V.I.I. All authors have read and agreed to the published version of the manuscript.

Funding: This research was funded by RFBR, grant number 20-33-90102 in the material synthesis part and grant number 19-03-00930 in the adsorption and characterization parts.

Data Availability Statement: Samples of the compounds HKUST-1 are available from the authors.

Acknowledgments: Electron microscopy characterization was performed in the Department of Structural Studies of Zelinsky Institute of Organic Chemistry, Moscow.

Conflicts of Interest: The authors declare no conflict of interest.

\section{References}

1. Li, Y.; Weser, G. Methane and Natural Gas Utilization. Energy Technol. 2020, 8, 2000460. [CrossRef]

2. Mokhatab, S.; Poe, W.A.; Mak, J.Y. Chapter 13-Unconventional Gas Processing. In Handbook of Natural Gas Transmission and Processing, 4th ed.; Gulf Professional Publishing: Houston, TX, USA, 2018; pp. 409-431.

3. Kumar, S.; Kwon, H.-T.; Choi, K.-H.; Lim, W.; Cho, J.; Tak, K.; Moon, I. LNG: An eco-friendly cryogenic fuel for sustainable development. Appl. Energy 2011, 88, 4264-4273. [CrossRef]

4. Li, X.; Chen, J. Adsorption of natural gas and its whole components on adsorbents. Adsorption 2011, 17, 949-954. [CrossRef]

5. Guecueyener, C.; van den Bergh, J.; Gascon, J.; Kapteijn, F. Ethane/Ethene Separation Turned on Its Head: Selective Ethane Adsorption on the Metal-Organic Framework ZIF-7 through a Gate-Opening Mechanism. J. Am. Chem. Soc. 2010, $132,17704$. [CrossRef]

6. Long, J.R.; Yaghi, O.M. The pervasive chemistry of metal-organic frameworks. Chem. Soc. Rev. 2009, 38, 1213-1214. [CrossRef]

7. Férey, G. Hybrid porous solids: Past, present, future. Chem. Soc. Rev. 2008, 37, 191-214. [CrossRef]

8. Joshi, J.N.; Zhu, G.; Lee, J.J.; Carter, E.A.; Jones, C.W.; Lively, R.P.; Walton, K.S. Probing Metal-Organic Framework Design for Adsorptive Natural Gas Purification. Langmuir 2018, 34, 8443-8450. [CrossRef]

9. Tsivadze, A.; Aksyutin, O.; Ishkov, A.; Fomkin, A.; Men'shchikov, I.; Pribylov, A.; Isaeva, V.; Kustov, L.; Shkolin, A.; Strizhenov, E. Adsorption of methane on an MOF-199 organometallic framework structure at high pressures in the range of supercritical temperatures. Prot. Met. Phys. Chem. Surf. 2016, 52, 24-29. [CrossRef]

10. Senkovksa, I.; Kaskel, S. High pressure methane adsorption in the metal-organic frameworks $\mathrm{Cu}_{3}(\mathrm{btc})_{2}, \mathrm{Zn}_{2}(\mathrm{bdc})_{2} \mathrm{dabco}$, and $\mathrm{Cr}_{3} \mathrm{~F}\left(\mathrm{H}_{2} \mathrm{O}\right)_{2} \mathrm{O}(\mathrm{bdc})_{3}$. Microporous Mesoporous Mater. 2008, 112, 108-115. [CrossRef]

11. Plonka, A.; Chen, X.; Wang, H.; Krishna, R.; Dong, X.; Banerjee, D.; Woerner, W.; Han, Y.; Li, J.; Parise, J. Light Hydrocarbon Adsorption Mechanisms in Two Calcium-Based Microporous Metal Organic Framework. Chem. Mater. 2016, 28, 1636-1646. [CrossRef]

12. Stoeck, U.; Senkovska, I.; Bon, V.; Krause, S.; Kaskel, S. Assembly of metal-organic polyhedra into highly porous frameworks for ethene delivery. Chem. Commun. 2015, 51, 1046-1049. [CrossRef] [PubMed]

13. Peng, Y.; Krungleviciute, V.; Eryazici, I.; Hupp, J.T.; Farha, O.K.; Yildirim, T. Methane Storage in Metal-Organic Frameworks: Current Records, Surprise Findings, and Challenges. J. Am. Chem. Soc. 2013, 135, 11887-11894. [CrossRef] [PubMed]

14. Isaeva, V.I.; Chernyshev, V.V.; Fomkin, A.A.; Shkolin, A.V.; Veselovsky, V.V.; Kapustin, G.I.; Sokolova, N.A.; Kustov, L.M. Preparation of novel hybrid catalyst with an hierarchical micro-/mesoporous structure by direct growth of the HKUST-1 nanoparticles inside Mesoporous Silica Matrix (MMS). Microporous Mesoporous Mater. 2020, 300, 110136. [CrossRef]

15. Hamon, L.; Jolimaitre, E.; Pirngruber, G.D. $\mathrm{CO}_{2}$ and $\mathrm{CH}_{4}$ Separation by Adsorption Using Cu-BTC Metal-Organic Framework. Ind. Eng. Chem. Res. 2010, 49, 7497-7503. [CrossRef]

16. Chuah, C.Y.; Samarasinghe, S.A.S.C.; Li, W.; Goh, K.; Bae, T.-H. Leveraging Nanocrystal HKUST-1 in Mixed-Matrix Membranes for Ethylene/Ethane Separation. Membranes 2020, 10, 74. [CrossRef]

17. He, Y.; Zhou, W.; Qian, G.; Chen, B. Methane storage in metal-organic frameworks. Chem. Soc. Rev. 2014, 43, 5657-5678. [CrossRef]

18. Isaeva, V.I.; Chernyshev, V.V.; Sokolova, N.A.; Kapustin, G.I. Modifying the Hydrophobic Properties of Metal-Organic Framework HKUST-1. Russ. J. Phys. Chem. A 2018, 92, 2391-2395. [CrossRef]

19. Qiu, S.; Du, J.; Xiao, Y.; Zhao, Q.; He, G. Hierarchical porous HKUST-1 fabricated by microwave-assisted synthesis with CTAB for enhanced adsorptive removal of benzothiophene from fuel. Sep. Purif. Technol. 2021, 271, 118868. [CrossRef]

20. Han, S.; Ciufo, R.; Meyerson, M.; Keitz, B.; Mullins, C. Solvent-free vacuum growth of oriented HKUST-1 thin films. J. Mater. Chem. A 2019, 7, 19396-19406. [CrossRef]

21. Glowniak, S.; Szczęśniak, B.; Choma, J.; Jaroniec, M. Mechanochemistry: Toward green synthesis of metal-organic frameworks. Mater. Today 2021, 46, 109-124. [CrossRef]

22. Usman, K.A.S.; Maina, J.W.; Seyedin, S.; Conato, M.T.; Payawan, L.M., Jr.; Dumée, L.F.; Razal, J.M. Downsizing metal-organic frameworks by bottom-up and top-down methods. NPG Asia Mater. 2020, 12, 58. [CrossRef]

23. Isaeva, V.I.; Eliseev, O.L.; Kazantsev, R.V.; Chernyshev, V.V.; Tarasov, A.L.; Davydov, P.E.; Lapidus, A.L.; Kustov, L.M. Effect of the support morphology on the performance of Co nanoparticles deposited on metal-organic framework MIL-53(Al) in Fischer-Tropsch synthesis. Polyhedron 2019, 157, 389-395. [CrossRef] 
24. Isaeva, V.I.; Tarasov, A.L.; Chernyshev, V.V.; Kustov, L.M. Control of Morphology and Size of Microporous Framework MIL-53(Al) Crystals by Synthesis Procedure. Mendeleev Commun. 2015, 25, 466-470. [CrossRef]

25. Kinik, F.P.; Uzun, A.; Keskin, S. Ionic Liquid/Metal-Organic Framework Composites: From Synthesis to Applications. ChemSusChem 2017, 10, 2842-2863. [CrossRef] [PubMed]

26. Ermer, M.; Mehler, J.; Kriesten, M.; Avadhut, Y.; Schulz, P.; Hartmann, M. Synthesis of the novel MOF hcp UiO-66 employing ionic liquids as a linker precursor. Dalton Trans. 2018, 47, 14426-14430. [CrossRef]

27. Guo, X.; Geng, S.; Zhuo, M.; Chen, Y.; Zaworotko, M.J.; Cheng, P.; Zhang, Z. The Utility of the Template Effect in Metal-Organic Frameworks. Coord. Chem. Rev. 2019, 391, 44-68. [CrossRef]

28. Shang, W.; Kang, X.; Ning, H.; Zhang, J.; Zhang, X.; Wu, Z.; Mo, G.; Xing, X.; Han, B. Shape and Size Controlled Synthesis of MOF Nanocrystals with the Assistance of Ionic Liquid Microemulsions. Langmuir 2013, 29, 13168-13174. [CrossRef]

29. Deiko, G.S.; Isaeva, V.I.; Kustov, L.M. New Molecular Sieve Materials: Composites Based on Metal-Organic Frameworks and Ionic Liquids. Pet. Chem. 2019, 59, 770-787. [CrossRef]

30. Liu, C.; Zhang, B.; Zhang, J.; Peng, L.; Kang, X.; Han, B.; Wu, T.; Sang, X.; Ma, X. Gas promotes the crystallization of nano-sized metal-organic frameworks in ionic liquid. Chem. Commun. 2015, 51, 11445-11448. [CrossRef]

31. Blanita, G.; Borodi, G.; Lazar, M.D.; Biris, A.-R.; Barbu-Tudoran, L.; Coldea, I.; Lupu, D. Microwave assisted non-solvothermal synthesis of metal-organic frameworks. RSC Adv. 2016, 6, 25967-25974. [CrossRef]

32. Isaeva, V.I.; Saifutdinov, B.R.; Chernyshev, V.V.; Vergun, V.V.; Kapustin, G.I.; Kurnysheva, Y.P.; Ilyin, M.M.; Kustov, L.M. Impact of the Preparation Procedure on the Performance of the Microporous HKUST-1 Metal-Organic Framework in the Liquid-Phase Separation of Aromatic Compounds. Molecules 2020, 25, 2648. [CrossRef] [PubMed]

33. Aguiar, L.W.; Otto, G.P.; Kupfer, V.L.; Fávaro, S.L.; Silva, C.T.P.; Moisés, M.P.; de Almeida, L.; Guilherme, M.R.; Radovanovic, E.; Girotto, E.M.; et al. Simple, fast, and low-cost synthesis of MIL-100 and MIL-88B in a modified domestic microwave oven. Mater. Lett. 2020, 276, 128127. [CrossRef]

34. Vaid, T.P.; Kelleya, S.P.; Rogers, R.D. Structure-directing effects of ionic liquids in the ionothermal synthesis of metal-organic frameworks. IUCrJ 2017, 4, 380-392. [CrossRef] [PubMed]

35. Yang, L.; Lu, H. Microwave-assisted Ionothermal Synthesis and Characterization of Zeolitic Imidazolate Framework-8. Chin. J. Chem. 2012, 30, 1040-1044. [CrossRef]

36. Silva, C.; Safadi, B.; Moises, M.; Meneguin, J.; Arroyo, P.; Favaro, S.; Girotto, E.; Radovanovic, E.; Rinaldi, A. Synthesis of Zn-BTC metal-organic framework assisted by a home microwave oven and their unusual morphologies. Mater. Lett. 2016, 182, 231-234. [CrossRef]

37. Bonhôte, P.; Dias, A.P.; Papageorgiou, N.; Kalyanasundaram, K.; Grätzel, M. Hydrophobic, highly conductive ambienttemperature molten salts. Inorg. Chem. 1996, 35, 1168-1178. [CrossRef]

38. Kashin, A.S.; Ananikov, V.P. A SEM study of nanosized metal films and metal nanoparticles obtained by magnetron sputtering. Russ. Chem. Bull. 2011, 60, 2602-2607. [CrossRef]

39. Blach, T.P.; Gray, E. Sieverts apparatus and methodology for accurate determination of hydrogen uptake by light-atom hosts. J. Alloys Compd. 2007, 31, 446-447. [CrossRef]

40. Sychev, V.V.; Wasserman, A.A.; Zagoruchenko, V.A.; Kozlov, A.D.; Spiridonov, G.A.; Tsymarnyi, V.A. Thermodynamic Properties of Ethane; Izdatel'stvo Standartov: Moscow, Russia, 1982; 305p. (In Russian)

41. Sychev, V.V.; Wasserman, A.A.; Zagoruchenko, V.A.; Kozlov, A.D.; Spiridonov, G.A.; Tsymarnyi, V.A. Thermodynamic Properties of Methane; Izdatel'stvo Standartov: Moscow, Russia, 1979; 351p. (In Russian)

42. Pawley, G.S. Unit-cell refinement from powder diffraction scans. J. Appl. Crystallogr. 1981, 14, 357-361. [CrossRef]

43. Zlokazov, V.B.; Chernyshev, V.V. MRIA-A program for a full profile analysis of powder multiphase neutron-diffraction time-offlight (direct and Fourier) spectra. J. Appl. Crystallogr. 1992, 25, 447-451. [CrossRef]

44. Smirnova, N.A.; Safonova, E.A. Ionic liquids as surfactants. Russ. J. Phys. Chem. 2010, 84, 1695-1704. [CrossRef]

45. Funasako, Y.; Nosho, M.; Mochida, T. Ionic liquids from copper(II) complexes with alkylimidazole-containing tripodal ligands. Dalton Trans. 2013, 42, 10138-10143. [CrossRef] [PubMed] 